\title{
Relative position and strengths of poly(A) sites as well as transcription termination are critical to membrane versus secreted $\mu$-chain expression during B-cell development
}

\author{
Gabriella Galli, ${ }^{1}$ Jeffrey W. Guise, ${ }^{2}$ Michael A. McDevitt, ${ }^{1}$ Philip W. Tucker, ${ }^{2}$ and Joseph R. Nevins ${ }^{1}$ \\ ${ }^{1}$ Howard Hughes Medical Institute, The Rockefeller University, New York, New York 10021 USA; ${ }^{2}$ Department of \\ Microbiology, Southwestern Medical School, University of Texas Health Science Center, Dallas, Texas 75235 USA
}

\begin{abstract}
During B-cell differentiation, there is a dramatic switch in the RNA products of the immunoglobulin $\mu$ heavy chain transcription unit. In the mature B cell there is roughly equal production of the $\mu_{s}$ and the $\mu_{\mathbf{m}}$ RNA, whereas in the antibody-secreting plasma cell there is nearly exclusive production of the $\mu_{\mathrm{s}}$ RNA. A plasmid containing the entire $\mu$ transcription unit was properly regulated when assayed by transient transfection in a B lymphoma and a plasmacytoma. In contrast, no such regulation was observed with separate plasmids that could produce only one or the other RNA. Instead, the $\mu_{m}$ poly(A) site was utilized more efficiently than the $\mu_{s}$ poly(A) site, irrespective of the cell type. We also found that transcription termination prior to the $\mu_{m} \operatorname{poly}(A)$ site in plasmacytomas contributes to preferential production of $\mu_{\mathrm{s}}$ RNA in these cells. Finally, reducing the distance between the two poly(A) sites improved the use of the $\mu_{m}$ site at the expense of the use of the $\mu_{s}$ in B lymphoma cells, suggesting a competition for a limiting factor. Such competition was not apparent in plasmacytomas. We conclude that relative poly(A) site strength and the position of the poly(A) sites within the transcription unit, coupled with a changing concentration of a limiting factor, as well as transcription termination prior to the $\mu_{\mathrm{m}}$ poly(A) site, all play a role in determining the expression of the $\mu$ locus during B-cell development.
\end{abstract}

[Key Words: IgM; poly(A) site choice; transcription termination]

Received March 2, 1987; revised version accepted, May 8, 1987.

Due to the complexity of the process of mRNA biogenesis in an animal cell, the regulation of the output of a gene can take many forms (Nevins 1983; Birnstiel et al. 1985; Padgett et al. 1986). This is particularly true for complex transcription units that generate multiple mRNA products. One such example is the immunoglobulin heavy-chain locus. Following assembly of the variable region gene components, the $\mu$ heavy chain of IgM appears in the cytoplasm of pre-B cells. After light-chain gene rearrangement, light chains and $\mu$ heavy chains are assembled into IgM, which is later co-expressed on the cell membrane $(\mathrm{m})$ with the closely linked downstream gene product, IgD. The pre- $\mathrm{B}$, immature $\mathrm{B}\left(\mathrm{mIgM}^{+}\right)$, and mature $\mathrm{B}\left(\mathrm{mIgM}^{+} \mathrm{mIgD}^{+}\right)$cells have the capacity to produce two forms of the $\mu$ protein; a heavy chain that can be secreted as an antibody molecule and a related heavy chain that can be inserted in the membrane as a receptor for antigen. When the mature B cell encounters antigen, there is an induction of proliferation and maturation that ultimately results in terminal differentiation and a switch to essentially exclusive production of the se- creted form of the $\mu$ heavy chain. As is the case for all of the heavy-chain genes, the mRNAs encoding the membrane and secreted forms of the IgM heavy chain $\mid \mu_{m}$ and $\mu_{\mathrm{s}}$ RNA) derive from the same transcription unit. They differ by sequences at the $3^{\prime}$ terminus that are encoded in distinct exons and specified by distinct poly $(\mathrm{A})$ addition sites (Alt et al. 1980; Early et al. 1980; Rogers et al. 1980). Thus, RNA processing at alternate poly(A) sites and subsequent splicing events govern the production of these two distinct mRNAs.

Our aim has been to identify the events in mRNA biogenesis that are regulated during B-cell maturation and that result in the selective production of the $\mu_{m}$ and $\mu_{s}$ mRNAs. Likely possibilities include factors that specifically recognize the poly(A) sites or factors that control the extent of transcription (i.e., termination factors) during the maturation of a B cell. We have employed plasmids containing the intact $\mu$ locus and derivatives with isolated poly(A) sites to probe for the presence of specific factors. In fact, we find no evidence for regulation via poly(A) site-specific factors, but rather we con- 
clude that the relative affinity of the poly|A| sites for a common factor and their position in the transcription unit are the key elements in determining expression in mature B cells. When cells terminally differentiate into plasma cells, transcription termination is largely responsible for exclusive production of the secreted mRNA.

\section{Results}

\section{Assays for $\mu$ expression and regulation}

The plasmid $\mathrm{p} \mu$ (Grosschedl and Baltimore 1985) contains a functionally rearranged $\mu$ gene inserted into an expression vector containing the polyoma early region to allow replication as a means of amplifying accumulation of the mRNAs and a mouse histone $\mathrm{H} 4$ gene to serve as an internal control (Fig. 1). We have assayed expression of $\mathrm{p} \mu$ by transfection into either a representative of a mature B cell (the B-lymphoma cell line M12.4) (Laskov et al. 1981) or a terminally differentiated plasma cell (the plasmacytoma J558L) (Oi et al. 1983). Since both lines have lost expression of their endogenous heavy chains $(\mu$ and $\alpha$, respectively) we can assay $p \mu$ in the absence of background. RNA was prepared $48 \mathrm{hr}$ after transfection and assayed for $\mu$ RNA sequences by S1 analysis.

Our initial experiment to assess whether the transfection of the $\mathrm{p} \mu$ plasmid into the M12 and J558L cell lines produced the expected regulation is shown in Figure 1C. A single Sl probe, as depicted at the bottom of the figure, was capable of measuring both $\mu_{\mathrm{s}}$ and $\mu_{\mathrm{m}}$. The $\mu_{\mathrm{s}}$ RNA protected the 3 '-end-labeled probe up to the poly(A) site yielding an SI fragment of 410 nucleotides. The $\mu_{m}$ RNA protected the probe to the point of the donor splice site within the $\mathrm{C} \mu 4$ exon yielding an $\mathrm{S} 1$ fragment of 225 nucleotides. We have also used a separate probe to detect the $\mu_{\mathrm{m}}$ RNA $3^{\prime}$ end and find the same quantitative result by this analysis as with the probe that detects the $\mu_{m}$ splice (data not shown). Transfection of the $\mathrm{p} \mu$ plasmid into the M12 B-lymphoma cell line yielded approximately equal amounts of the $\mu_{\mathrm{s}}$ and $\mu_{m}$ RNA. In contrast, production of the $\mu_{s}$ RNA dominated when the $\mu$ plasmid was transfected into the plasmacytoma $5558 \mathrm{~L}$. The change in the ratio of the RNAs varied between $1: 5$ and $1: 8$ over the course of a number of assays. We therefore conclude that the transfection assay of the $\mu$ gene closely approximates the regulation of $\mu_{\mathrm{m}}$ and $\mu_{\mathrm{s}}$ RNA production.

\section{Transfection assays for site-specific processing factors}

We have tested possible mechanisms for poly(A) site choice in the Ig locus through the assay of derivatives of the $p \mu$ plasmid. The plasmid $\mu_{\mathrm{s}}$ contains the $\mu_{\mathrm{s}}$ poly(A) site but no $\mu_{m}$ site (Fig. 2A). Conversely, the $\mu_{s}$ poly(A)
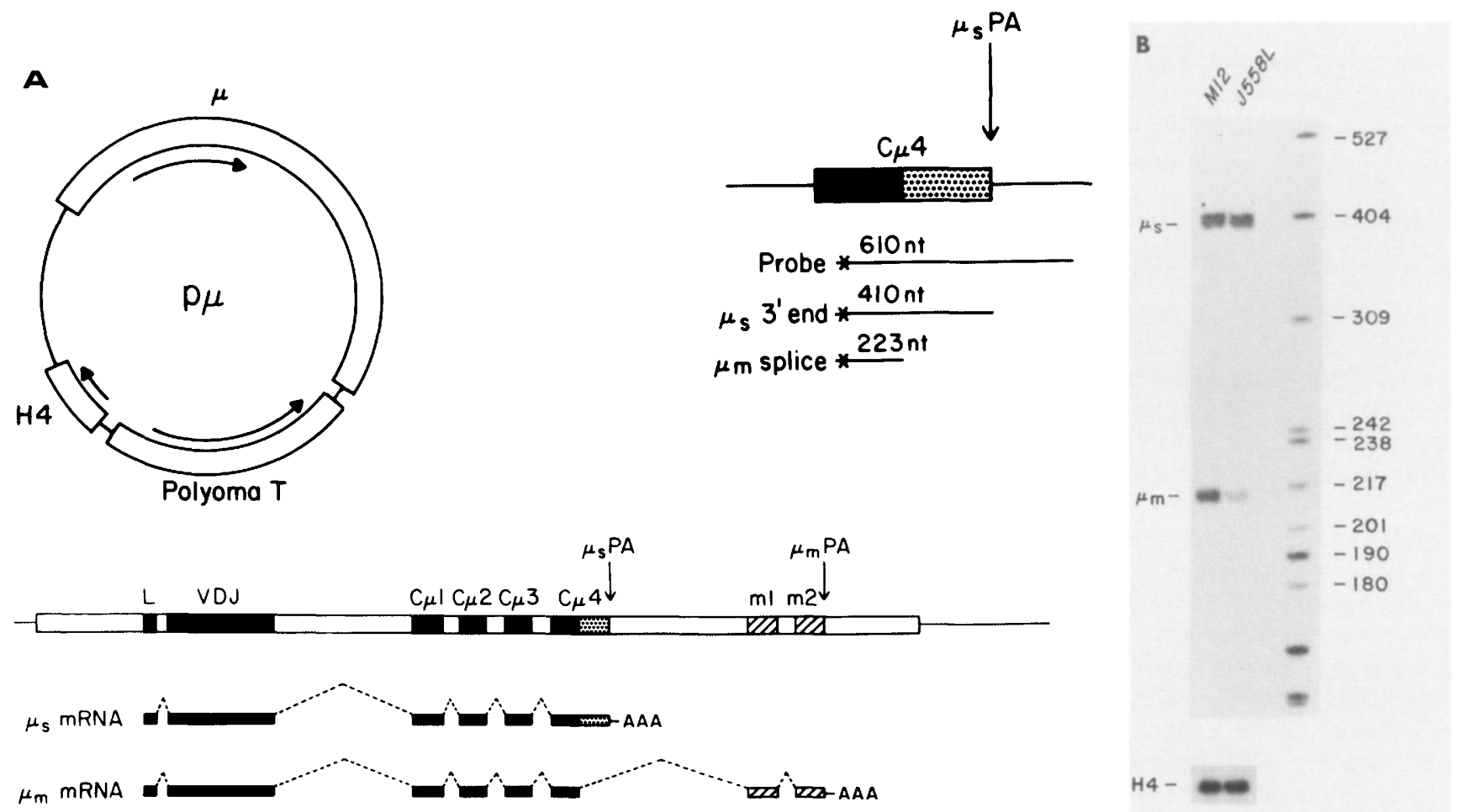

Figure 1. Structure of the $\mathrm{p} \mu$ plasmid and expression during transient transfection assays. $(A)$ The p $\mu$ plasmid $(G r o s s c h e d l$ and Baltimore 1985$)$ contains a rearranged mu gene $(9.1 \mathrm{~kb})$, a mouse histone $\mathrm{H} 4$ gene $(0.6 \mathrm{~kb})$, and the early region of polyoma $(3.6 \mathrm{~kb})$ in a pBR322 vector $(2.0 \mathrm{~kb})$. Arrows indicate direction of transcription. Shown below is the $\mu$ transcription unit and the exon structures of the $\mu_{\mathrm{s}}$ and $\mu_{\mathrm{m}}$ mRNAs. (B) S1 mapping of RNAs produced from M12 and J558L cells transfected with the p $\mu$ plasmid. About $20 \mu \mathrm{g}$ of total RNA was hybridized to a 3'-end-labeled probe depicted at the left. Hybridization to the $\mu_{\mathrm{s}}$ mRNA protects a fragment of 410 nucleotides [to the $\mu_{s}$ poly(A) site]. Hybridization to the $\mu_{m}$ mRNA protects a fragment of 223 nucleotides (to the $\mu_{m}$ splice donor). H4 RNA produced from $\mathrm{p} \mu$ in each transfection was quantitated by 5' S1 analysis (Grosschedl and Baltimore 1985). 


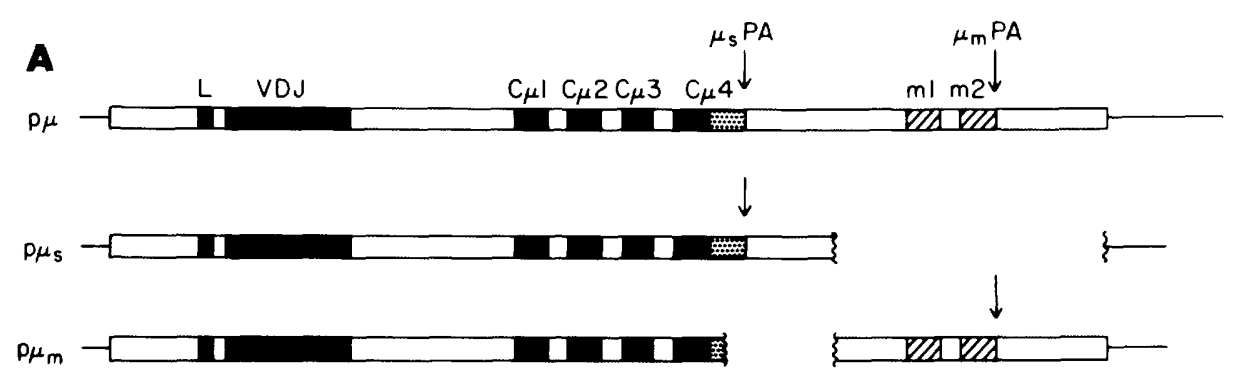

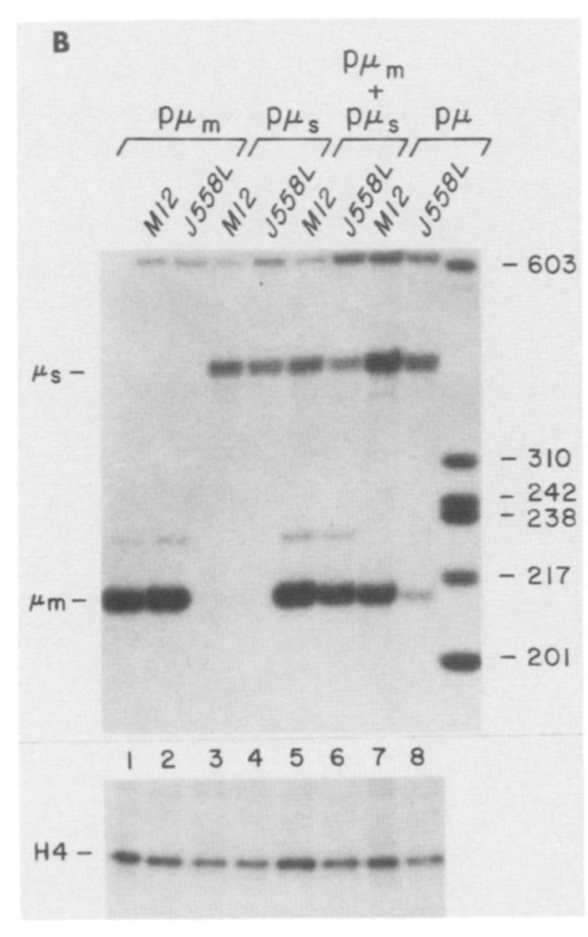

Figure 2. Structure and expression of $\mathrm{p} \mu$ plasmids with single poly $(\mathrm{A})$ sites. $(A)$ The $\mathrm{p} \mu_{\mathrm{s}}$ plasmid was constructed by deleting a $B c l I-E c o R V$ fragment leaving $1190 \mathrm{nu}$ cleotides downstream of the $\mu$ s poly(A) site. The $\mathrm{p} \mu_{\mathrm{m}}$ plasmid was constructed by deleting an $E c o R V-X h o$ I fragment leaving intact the splice donor sequence for $\mu_{\mathrm{m}}$ in the $C \mu 4$ exon. $(B)$ Transfections and $S 1$ assays were performed as described in Fig. 2. For the assays shown in lanes 5 and 6 , equal amounts of $\mathrm{p} \mu_{\mathrm{m}}$ and $\mathrm{p} \mu_{\mathrm{s}}$ were cotransfected. site has been deleted from the $\mathrm{p} \mu_{\mathrm{m}}$ plasmid. In each case, the RNA that can be produced is of normal structure. When these plasmids were transfected into MI2 cells and J558L cells, the results shown in Figure 2B were obtained. First, there was no cell preference for RNA production. For instance, the level of $\mu_{s}$ RNA from $p \mu_{s}$ was the same in transfection of $\mathrm{Ml} 2$ and $\mathrm{J} 558 \mathrm{~L} ; \mu_{\mathrm{m}}$ RNA from $\mathrm{p} \mu_{\mathrm{m}}$ was equal in both cell types. An inspection of H4 RNA production from the various plasmids indicated that there were no effects from transfection efficiency or plasmid copy number that contributed to the levels of immunoglobulin RNAs. Since there is no cell-specific expression from $\mathrm{p} \mu_{\mathrm{s}}$ or $\mathrm{p} \mu_{\mathrm{m}}$ it would appear unlikely that the $\mu_{\mathrm{s}} / \mu_{\mathrm{m}}$ switch was due to specific factors acting at the poly(A) sites. In addition, the $\mu_{m}$ production dominated over $\mu_{\mathrm{s}}$ in each case, including when the two plasmids were cotransfected. Particularly striking was the ratio of $\mu_{m} / \mu_{s}$ in J558L cells. When derived from separate plasmids, the $\mu_{m}$ RNA was sixfold more abundant than the $\mu_{\mathrm{s}}$ RNA. However, when the $\mu_{\mathrm{m}}$ RNA was produced from the p $\mu$ plasmid ( $\mu_{m}$ positioned downstream of $\mu_{s}$ ), there was five times more $\mu_{s}$ RNA than $\mu_{m}$. Clearly, the position within the transcription unit appears critical.

The above results suggested that the $\mu_{m}$ poly(A) site may be stronger than the $\mu_{s}$ poly(A) site and offered an explanation for the near-equal use of the two poly $(A)$ sites in the M12 lymphoma cells. Namely, the inefficiency of the $\mu_{\mathrm{s}}$ site could allow transcripts to go uncleaved and thus available for cleavage at the $\mu_{\mathrm{m}}$ site. If the $\mu_{m}$ site was stronger, these "available transcripts" could be processed at higher efficiency. If true, then placing the $\mu_{\mathrm{m}}$ site first in the transcription unit should eliminate use of the $\mu_{\mathrm{s}}$ site. Such an experiment was performed using the $\mathrm{p} \mu_{\mathrm{m} / \mathrm{s}}$ plasmid depicted in Figure $3 A$. The transfection efficiency of the $\mathrm{p} \mu_{\mathrm{m} / \mathrm{s}}$ plasmid was low compared with the $\mathrm{p} \mu$ plasmid as judged by the reduced $\mathrm{H} 4$ signal. This was a reproducible finding with this plasmid, the reason for which is not clear. However, the efficiency was the same in two cell lines and the critical aspect of the experiment is the ratio of $\mu_{\mathrm{s}}$ to $\mu_{\mathrm{m}}$. There was no apparent use of the downstream $\mu_{\mathrm{s}}$ poly(A) site from the $\mathrm{p} \mu_{\mathrm{m} / \mathrm{s}}$ plasmid when $3^{\prime}$ ends were assayed as shown in Figure 3B. Although it is possible that a mRNA using the $\mu_{s}$ poly(A) site might be unstable due to an altered exon structure, we could find no evidence whatsoever for use of the $\mu_{s}$ poly(A) site, even in a long exposure of the autoradiogram (lanes $3^{\prime}$ and $4^{\prime}$ ).

From these results we draw several conclusions. First, there is no evidence for trans-acting factors that are poly(A) site specific. Second, the $\mu_{m}$ poly(A) site appears 


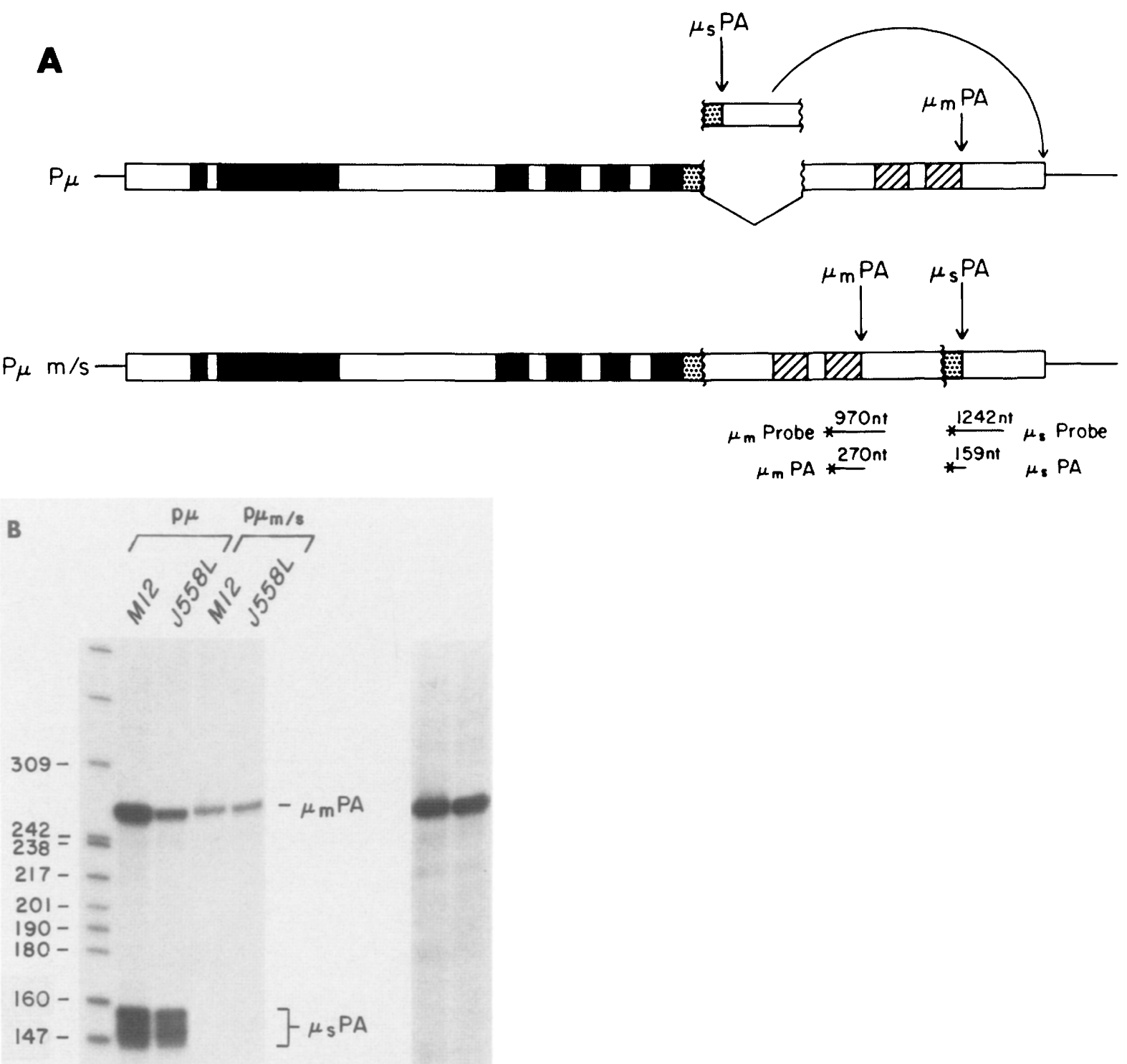

Figure 3. Structure and expression of the $\mathrm{p} \mu_{\mathrm{m} / \mathrm{s}}$ plasmid. $(A)$ In the $\mathrm{p} \mu_{\mathrm{m} / \mathrm{s}}$ plasmid the $B c l$ fragment containing the $\mu_{s}$ poly $(A)$ site was placed 710 nucleotides downstream of the $\mu_{\mathrm{m}}$ poly(A) site. The S1 probes used for the assay of $\mu_{\mathrm{s}}$ and $\mu_{\mathrm{m}} 3^{\prime}$ ends are depicted at the bottom of the figure. $(B) \mathrm{Sl}$ mapping of RNAs produced from M12 and J558L cells transfected with the $\mathrm{p} \mu_{\mathrm{m} / \mathrm{s}}$ plasmid. Hybridization to $\mu_{\mathrm{s}}$ and $\mu_{\mathrm{m}}$ RNA protects fragments of 159 nucleotides [to the $\mu_{\mathrm{s}}$ poly $(\mathrm{A})$ site] and 270 nucleotides [to the $\mu_{\mathrm{m}}$ poly(A) sitel. Lanes $3^{\prime}$ and $4^{\prime}$ are $3 \times$ longer exposures of lanes 3 and 4.

to be intrinsically stronger (more efficient) than the $\mu_{s}$ poly(A) site. When the poly(A) sites were on separate plasmids, the $\mu_{m}$ RNA was the dominant product and if the $\mu_{\mathrm{m}}$ site were placed in front of the $\mu_{\mathrm{s}}$ site within the same transcription unit, we could find no evidence for use of the $\mu_{s}$ poly(A) site. This result thus provides a basis for competition between two linked poly(A) sites.

Differential transcription termination within the $\mu$ transcription unit during B-cell maturation

If plasma cells retain the ability to efficiently use the $\mu_{m}$ poly(A) site, then what is responsible for the observed decline in its use when linked to $\mu_{s}$ ? Transcription termination could be a mechanism, but previous reports have often argued against a transcription termination mechanism for the $\mu_{\mathrm{m}}$ to $\mu_{\mathrm{s}}$ switch. Danner and Leder (1985) reported expression of membrane containing RNA in plasmacytomas but these experiments did not measure transcription rates; they only demonstrated the presence of these sequences. Ruether et al. (1986) did measure transcription and suggested that expression of an adenovirus-borne $\mu$ locus in plasmacytoma cells did not terminate prior to the $\mu_{m}$ exons. Likewise, Yuan and Tucker (1984) did not find evidence for transcription ter- 
mination in the $\mu$ locus in lipopolysaccharide (LPS)stimulated lymphocytes which produce large amounts of $\mu_{\mathrm{s}}$ RNA. In considering possible reasons why these transcription measurements may not have detected termination, it became clear that several factors could play a role. The choice of hybridization probes could be an important consideration. If transcription proceeded unabated through the $\mu$ exons but stopped just prior to the $\mu_{m}$ poly(A) site, formation of the $\mu_{m}$ RNA would be prevented but transcription termination would not be scored unless the probe assayed sequences immediately adjacent to the poly(A) site. Such probes were not used in the previous studies cited above. In addition, the production of sterile $\mu$ transcripts often initiated in the $J_{\mathrm{H}}-C_{\mu}$ intron (Alt et al. 1982; Nelson et al. 1983; Lennon and Perry 1985) could obscure specific termination events in cell lines. That is, there is no way to distinguish transcription from a productive allele from aberrant transcription that derives from a nonproductive allele. Although in some instances it appears that sterile transcripts may obey the normal termination signals, this may not always be the case. With this in mind, we examined the extent of transcription across the $\mu$ locus, using transient transfections of $\mathrm{M} 12$ and $5558 \mathrm{~L}$ cells with the $\mathrm{p} \mu$ plasmid where endogenous $\mu$ transcription does not contribute to the transcription measurement, and using as one of the probes for hybridization a small DNA fragment of 200 nucleotides that spans the $\mu_{m}$ poly(A) site (Fig. 4).

M12 cells and J558L cells were transfected with the $\mu$ plasmid and nuclei were isolated $40 \mathrm{hr}$ later. Nascent chains were labeled by in vitro incubation, and the nuclear RNA was isolated and then hybridized to filters bearing M13 probes representing various regions of the $\mu$ transcription unit. One such example is shown in Figure 4 and a quantitation of the results of several independent experiments is given in Table 1. Analysis of transcription of the $\mathrm{p} \mu$ plasmid in $\mathrm{M} 12$ cells revealed equimolar rates across the entire transcription unit; thus, no evidence for termination. In contrast, transcription of $p \mu$ in J558L cells dropped sharply near the $\mu_{m}$ poly $(A)$ site thus indicating cell-specific termination prior to the $\mu_{m}$ poly(A) site. Of course, this interpretation depends on there being no specific loss of these sequences /degrada-
Table 1. Relative transcription rates across the $\mu$ locus in M12 and I558L transfections

\begin{tabular}{lllllll}
\hline & \multicolumn{5}{c}{ Relative transcription rates } \\
\cline { 2 - 7 } Cell line & $\mathrm{a}$ & $\mathrm{b}$ & $\mathrm{c}$ & $\mathrm{d}$ & $\mathrm{e}$ \\
\hline M12 & 1.0 & 1.2 & 0.9 & 0.6 & 1.1 \\
J558L & 1.0 & 0.7 & 0.5 & 0.1 & 0.1 \\
\hline
\end{tabular}

Hybridization of labeled nuclear RNA to slot blots of sensestrand M13 DNAs, as shown in Fig. 4, were scanned with a densitometer. The densitometer values were corrected for the size of the hybridizing DNA and normalized to the value for the " $a$ " probe. The data shown are the average of three independent experiments. Background hybridization as measured with Ml3 DNA was undetectable in the exposures employed.

tion) in the isolated nuclei, a possibility judged to be very unlikely given past results with isolated nuclei. There was some evidence of termination in the region between the $\mu_{s}$ and $\mu_{m}$ poly $(A)$ sites because hybridization to probe $\mathrm{c}$ was reduced $50 \%$. However, with the probe that spanned the $\mu_{m}$ poly(A) site (probe d), it was clear that very few polymerases proceeded to this point. Furthermore, the difference in transcription rates across the $\mu_{m}$ poly $(A)$ site in $M 12$ compared with $J 558 \mathrm{~L}$ was sixto tenfold, thus fully accounting for the change in mRNA levels. Therefore, we conclude from this data that termination of transcription prior to the $\mu_{m}$ poly(A) site can be a significant factor in the switch in production of $\mu_{m}$ and $\mu_{s}$ mRNAs when B cells undergo terminal differentiation to plasma cells. This conclusion is, in fact, consistent with a recent analysis of the extent of $\mu$ transcription in a number of hybridomas and plasmacytomas which indicated that in many cases transcription termination could be a major factor in the decline of $\mu_{m}$ RNA production in IgM-secreting cells /Kelley and Perry 1986). In those cases where there was little termination, transcription may well have derived from nonproductive alleles. Alternatively, there may simply be some cellular variation in the extent to which termination contributes to the plasma cell phenotype. Our experiments indicate that transcription termination certainly can be a factor.
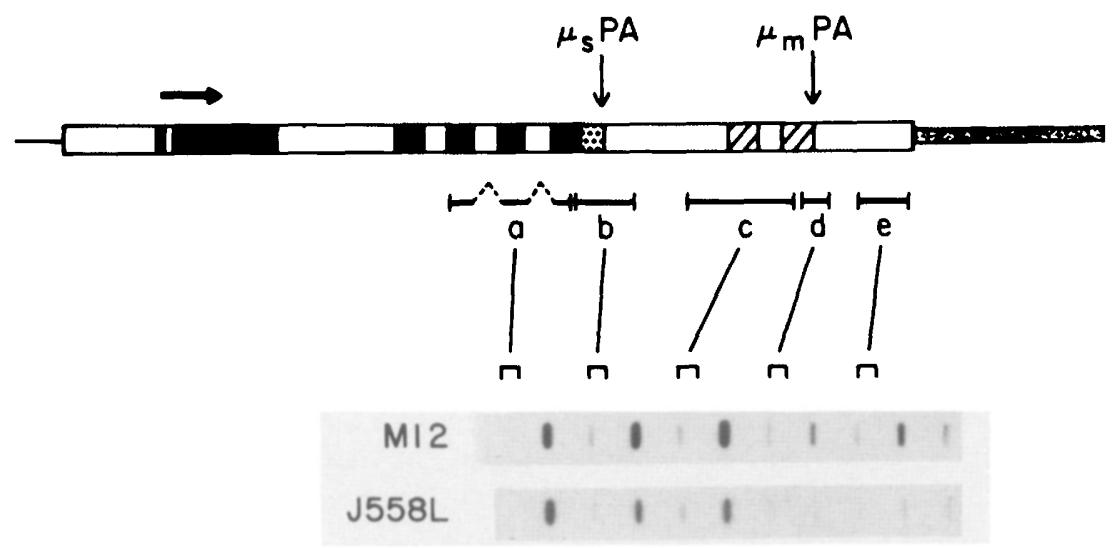

Figure 4. Transcription rate analysis of $\mathrm{p} \mu$ expression in M12 and J558L cells. Shown at the top of the figure is a map of the $\mu$ transcription unit and the M13 probes used for hybridization. The exact derivation of the probes is described in Materials and methods. The M13 DNA probes were immobilized on nitrocellulose filters and used for hybridization of RNA labeled in vitro from nuclei of $\mathrm{Ml} 2$ and $\mathrm{J558 \textrm {L }}$ cells transfected with $\mathrm{p} \mu$. To the right of each specific probe (sense strand) is the hybridization to an M13 probe of the opposite strand. Finally, hybridization to M13 DNA with no insert yielded no detectable hybridization. 


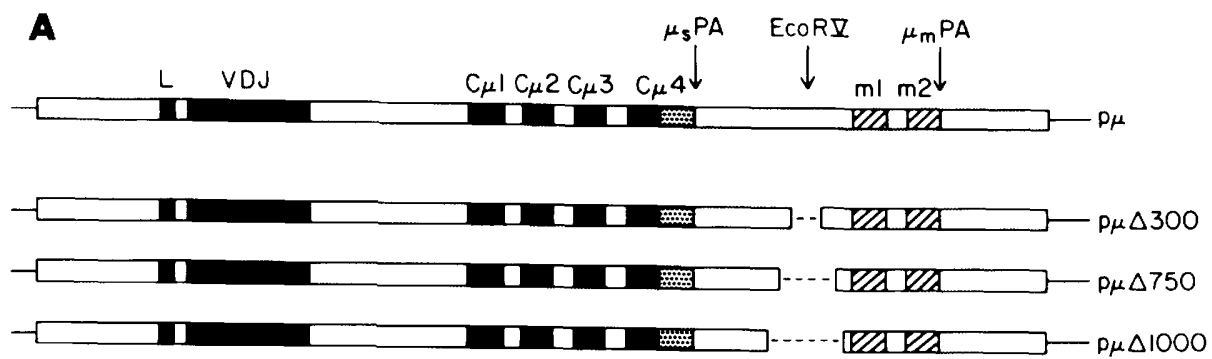

Figure 5. Structure and expression of $\mathrm{p} \mu$ intron deletion mutants in $5558 \mathrm{~L}$ transfections. $|A|$ Schematic diagram of the structure of the intron deletions. Shown is the structure of the wildtype $\mathrm{p} \mu$ and the position of an EcoRV site within the $C \mu 4 / \mathrm{Ml}$ intron that was used for Bal3l deletion. Below is depicted the structure of three deletion mutants in which 300 nucleotides $(\mathrm{p} \mu \Delta 300), 750$ nucleotides ( $\mathrm{p} \mu \Delta 750)$, and 1000 nucleotides $(\mathrm{p} \mu \Delta 1000)$ have been deleted. The structure of these deletions has been determined by restriction analysis and thus the exact end points of the deletion are not known. (B) S1 mapping of RNAs produced in J558L cells transfected with $\mathrm{p} \mu$ and the intron deletions. RNAs were assayed as described in Fig. 1.

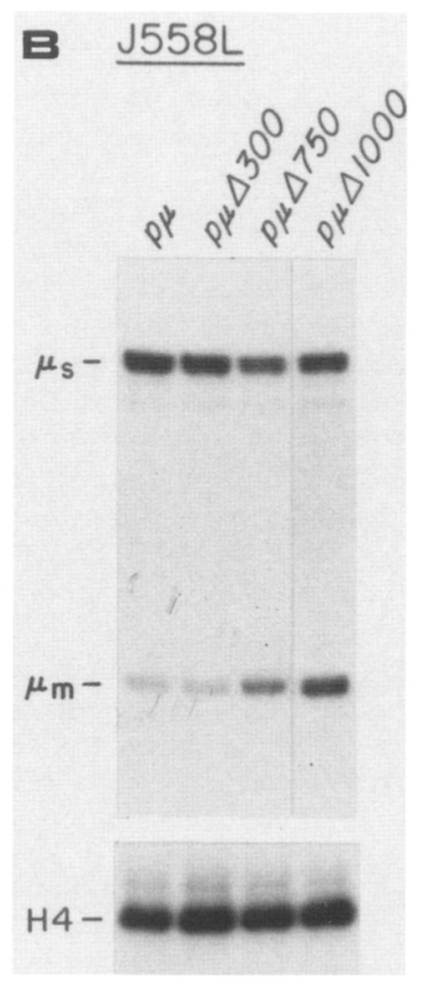

Deletion of a portion of the $\mu_{\mathrm{s}}-\mu_{\mathrm{m}}$ intron alters transcription termination in $1558 \mathrm{~L}$ cells and increases $\mu_{\mathrm{m}}$ RNA production

From the preceding results, we conclude that the increased ratio of $\mu_{\mathrm{s}}$ to $\mu_{\mathrm{m}}$ RNA in J558L cells is in large part due to termination of transcription prior to the $\mu_{m}$ poly(A) site. If such termination were mediated by a cell-specific factor recognizing a cis-acting $\mu$ sequence, then elimination of the target sequence should have the same effect as the absence of the factor (as in M12 cells) and thus revert expression to that seen in the M12 cells. We have tested this possibility by generating deletions in the intron between the $\mu_{\mathrm{s}}$ poly(A) site and the $\mu_{\mathrm{m}}$ exons, as shown in Figure 5A. These plasmids, along with the wild-type $\mathrm{p} \mu$ plasmid, were transfected into J558L cells and $\mu$ RNA expression was assayed both by S1 analysis and by transcription rate measurement. As seen before, $\mu_{\mathrm{s}}$ RNA was the predominant product of the $\mathrm{p} \mu$ plasmid. However, as sequence was deleted from the intervening region, there was a change in the ratio in favor of the $\mu_{m}$ RNA such that the $p \mu-1000$ plasmid produced an equal amount of $\mu_{m}$ and $\mu_{s}$ RNA (Fig. 5B). Furthermore, we note that the change in $\mu_{s} / \mu_{m}$ ratio was not at the expense of the $\mu_{s}$ RNA; production of the $\mu_{s}$ RNA remained constant. Rather, as the size of the deletion increased, there was a parallel increase in the $\mu_{\mathrm{m}}$ RNA production resulting in a rise in the level of total $\mu$ RNA. As shown in Figure 6 and summarized in Table 2, this increase in $\mu_{m}$ RNA production in the $5558 \mathrm{~L}$ cells was accompanied by an increased frequency of transcription of the sequences immediately downstream of the $\mu_{m}$ poly $(\mathrm{A})$ site. The rate of transcription of the downstream sequences in the p $\mu$ plasmid was only $10 \%$ that of the $C_{\mu}$ exon sequences. However, transcription of the $\mu_{\mathrm{m}}$ downstream sequence increased fivefold from the $\mathrm{p} \mu-1000$ plasmid. We thus conclude that the deletion of intervening sequence between the $\mu_{s}$ poly|A) site and the $\mu_{m}$ exons alters the extent of transcription of the locus

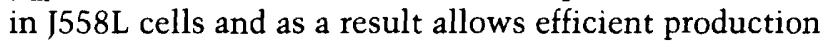
of $\mu_{m}$ mRNA in the plasmacytoma. This result must also mean that processing of transcripts from $p \mu$ to produce $\mu_{s}$ RNA is not $100 \%$ efficient. Otherwise, the increase in $\mu_{m}$ production would have resulted in a decrease in $\mu_{\mathrm{s}}$.

Analysis of $\mu_{\mathrm{s}} / \mu_{\mathrm{m}}$ RNA production in M12 cells directed by intron-deletion mutants provides evidence for $\operatorname{poly}(A)$ site competition

Finally, we have also assayed for the production of $\mu_{\mathrm{s}}$ and $\mu_{m}$ RNA from the various deletion mutants in the M12 lymphoma cell line. In these cells, there was little or no termination of $\mu$ transcription prior to the $\mu_{m}$ poly(A) site (Fig. 4). Thus, the signal for termination that is recognized in $\mathrm{J} 558 \mathrm{~L}$ cells is apparently not utilized in M12 cells, indicating that the deletions should have no effect on transcription of the $\mu_{m}$ poly(A) site sequences in the M1 2 cells. This was in fact true (data not shown). Likewise, we anticipated that mRNA production in M12 cells would be unaffected by the deletions. However, such was not the case as shown in Figure 7 and summarized in Table 3 . In fact, there was a dramatic change in the ratio of $\mu_{\mathrm{s}} / \mu_{\mathrm{m}}$ RNA as a function of deletion of the intron sequences. However, the nature of the change in ratio was quite different from that seen in the $\mathrm{J} 558 \mathrm{~L}$ cells. In the M12 cells, the level of $\mu_{m}$ RNA increased at 

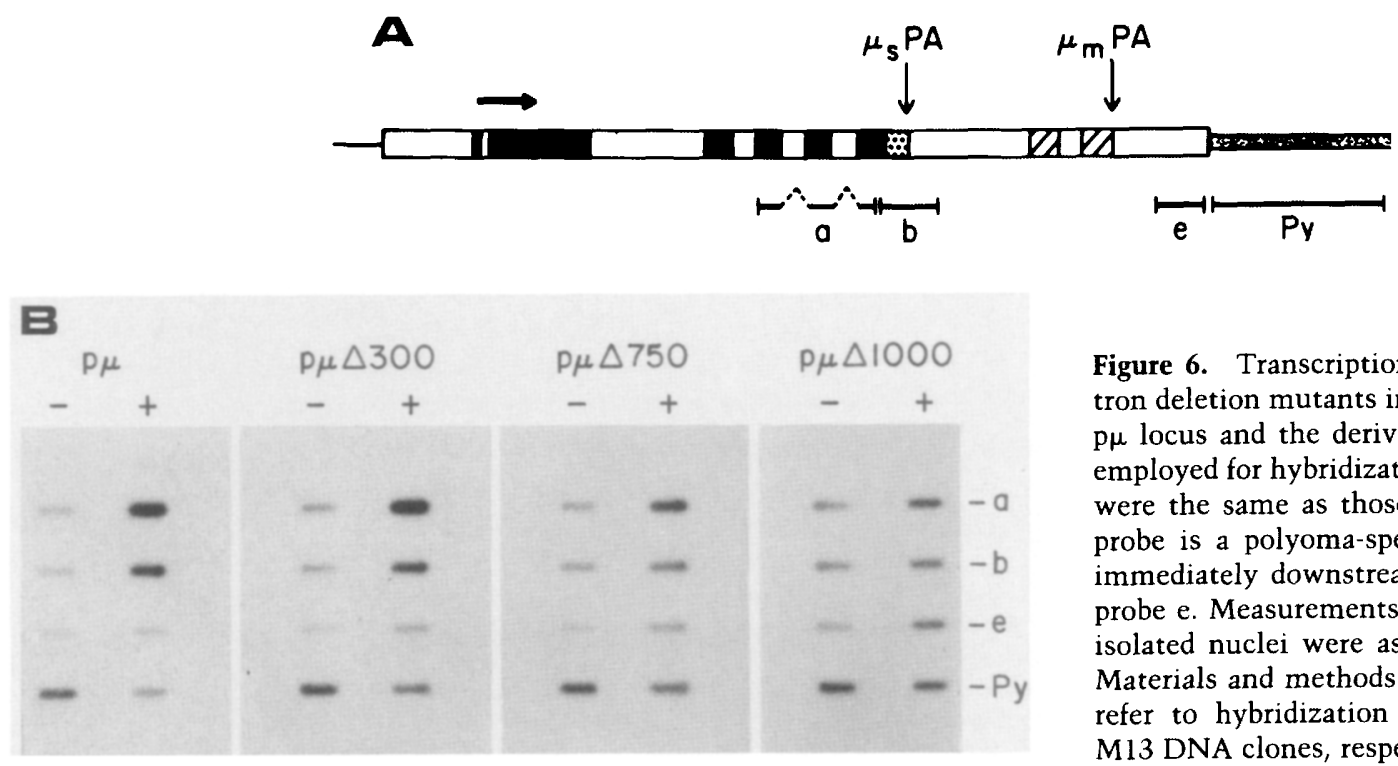

Figure 6. Transcription rate analysis of $\mathrm{p} \mu$ intron deletion mutants in $1558 \mathrm{~L}$ transfections. $(A)$ $\mathrm{p} \mu$ locus and the derivation of the M13 probes employed for hybridization. $(B)$ Probes $\mathrm{a}, \mathrm{b}$, and $\mathrm{e}$ were the same as those used in Fig. 4. The Py probe is a polyoma-specific sequence that lies immediately downstream of the $\mu$ sequence in probe e. Measurements of transcription rates in isolated nuclei were as described in Fig. 4 and Materials and methods. Lanes labeled + and refer to hybridization to sense and antisense M13 DNA clones, respectively. the expense of the $\mu_{\mathrm{s}}$ RNA; the total $\mu$ RNA remained constant. This would be expected if there was no change, as a function of the deletions, in the overall rate or extent of transcription, which indeed was the case. The increased $\mu_{m}$ RNA production coupled with a decreased production of $\mu_{s}$ RNA suggests a competition for a common limiting factor responsible for the production of the two RNAs that is affected by the amount of intron sequence in the transcription unit. Furthermore, the competition is cell specific since it is only evident in the M12 cell with no evidence for such in the $5558 \mathrm{~L}$ cell, indicating that the common factor is no longer limiting in these cells.

\section{Discussion}

Our data suggest that, together with transcription termination, relative poly(A) site strength coupled with position of the poly(A) site within the transcription unit are critical factors in determining the expression from the $\mu$ locus. From the analysis of $\mu$ plasmids containing single poly(A) sites it appears unlikely that there are cell-specific factors for each poly(A) site. That is, we found no evidence for cell-specific regulation when the poly $(A)$ sites were not together in the same transcription unit. The most straightforward interpretation of the data is that there is a single factor that is utilized by both poly(A) sites, and the inefficiency of the $\mu_{s}$ site ensures the availability of transcripts to be processed at the $\mu_{m}$ site. Previous experiments utilizing the late adenoviral transcription unit had indicated that poly $(\mathrm{A})$ site formation occurred during transcription; that is, the nascent RNA chain is the substrate for cleavage (Nevins and Darnell 1978). The order of the poly(A) sites in a transcription unit thus becomes a critical factor since there is polarity to the process [the proximal poly (A) site is seen before the distal site]. From the data presented here, we would conclude that the $\mu_{s}$ poly(A) site is rather weak and therefore allows a number of transcripts to go uncleaved at this site. In contrast, the $\mu_{m}$ poly(A) site appears to be quite efficient such that transcripts that go unprocessed at the $\mu_{s}$ site might well be processed at the $\mu_{m}$ site. In the mature $B$ cell this results in near-equal use of the two poly(A) sites. In the plasma cell, the use of the dominant $\mu_{m}$ site is reduced by transcription termination, thus yielding predominantly $\mu_{s}$ RNA.

The analysis of $\mu$ RNA expression from the intron deletions provides further insight into this process. By removing sequences in the large intron between the two poly(A) sites, there was an increased production of $\mu_{m}$ RNA and a simultaneous decrease in $\mu_{s}$ RNA in the M12 cell line. This occurred in the absence of any change in transcription of the locus. We would offer the following as an explanation for this observation. Although poly(A) site selection likely takes place on the nascent transcript (Nevins and Darnell 1978), it may not occur instantly. Thus, the relative "nearness" of two poly(A) sites and their relative "strength" may dictate their frequency of use. In this instance, the stronger $\mu_{m}$ poly(A) site is brought closer to the weak $\mu_{\mathrm{s}}$ site by virtue of the deletions. We suggest that this change in spacing is sufficient to allow the $\mu_{\mathrm{m}} \operatorname{poly}(\mathrm{A})$ site to be recognized before the $\mu_{\mathrm{s}}$ site is processed. Why, then, does this not occur in the J558L cells? Clearly, competition can only take place if a common factor is limiting. Although we found no evidence for a rise in a factor in the experiments employing single poly(A) sites, analysis of the intron deletions in the M12 cell line indeed suggest that competition occurs when two poly(A) sites are linked in the same transcription unit. Furthermore, the data suggest that the factor is no longer limiting in the $\mathrm{J} 558 \mathrm{~L}$ cells.

Two other reports have recently described changes in $\mu_{s} / \mu_{m}$ ratios as a function of intron deletions. In one study, the majority of deletions had no effect on $\mu_{m}$ production in plasmacytomas (Danner and Leder 1985). Only when the $\mu_{s}$ poly $(A)$ site was impaired was there an increase in $\mu_{m}$ RNA. However, the largest deletion was no more than 350 nucleotides, a size that produced little 
Table 2. Relative transcription rates across the $\mu$ locus in J558L transfection of intron deletions

\begin{tabular}{lllll}
\hline & \multicolumn{4}{c}{ Probe } \\
\cline { 2 - 5 } Plasmid & $\mathrm{a}$ & $\mathrm{b}$ & $\mathrm{e}$ & Py \\
\hline $\mathrm{p} \mu$ & 1.0 & 0.7 & 0.10 & 0.06 \\
$\mathrm{p} \mu \Delta 300$ & 1.0 & 0.6 & 0.15 & 0.11 \\
$\mathrm{p} \mu \Delta 750$ & 1.0 & 0.6 & 0.40 & 0.34 \\
$\mathrm{p} \mu \Delta 1000$ & 1.0 & 0.8 & 0.53 & 0.45 \\
\hline
\end{tabular}

Hybridization of labeled nuclear RNA to slot blots of sensestrand M13 DNA, as depicted in Fig. 6, were scanned with a densitometer. The values were corrected for the size of the hybridizing sequence and normalized to the value for the " $a$ " probe. The data presented are the average of three independent experiments.

Table 3. $\mu$ RNA production from intron deletions in $M 12$ and $1558 \mathrm{~L}$

\begin{tabular}{llllllll}
\hline & \multicolumn{3}{c}{$\mathrm{M} 12$} & & \multicolumn{3}{c}{$\mathrm{J} 558 \mathrm{~L}$} \\
\cline { 2 - 4 } \cline { 5 - 7 } Plasmid & $\mu_{\mathrm{s}}$ & $\mu_{\mathrm{m}}$ & $\mu_{\mathrm{m}} / \mu_{\mathrm{s}}$ & & $\mu_{\mathrm{s}}$ & $\mu_{\mathrm{m}}$ & $\mu_{\mathrm{m}} / \mu_{\mathrm{s}}$ \\
\hline $\mathrm{p} \mu$ & 1.0 & 0.6 & 0.6 & & 1.0 & 0.10 & 0.1 \\
$\mathrm{p} \mu \Delta 300$ & 0.92 & 0.8 & 0.9 & & 1.0 & 0.22 & 0.2 \\
$\mathrm{p} \mu \Delta 750$ & 0.37 & 1.3 & 3.5 & & 0.8 & 0.64 & 0.8 \\
$\mathrm{p} \mu \Delta 1000$ & 0.25 & 1.4 & 5.6 & & 0.9 & 0.98 & 1.1 \\
\hline
\end{tabular}

Presented are relative levels of $\mu_{\mathrm{s}}$ and $\mu_{\mathrm{m}}$ RNAs determined by densitometric scanning of autoradiograms of $\mathrm{S} 1$ analyses as depicted in Figs. 5 and 7. The data are normalized to the value of the $\mu_{\mathrm{s}}$ RNA expressed from the $\mathrm{p} \mu$ plasmid in each transfection.

effect in our experiments. More recently, Peterson and Perry (1986) have reported experiments regarding the role of intron sequences in the regulation of the $\mu$ gene. Specifically, larger deletions of intron sequences altered the $\mu_{\mathrm{s}} / \mu_{\mathrm{m}}$ ratio in favor of $\mu_{\mathrm{m}}$, thus consistent with the results we have described here. However, these authors did not measure transcription rates nor the absolute levels of the two RNAs, rather just ratios. Based on their results, Peterson and Perry (1986) suggested that there was a competition between the formation of the $C \mu_{4}$ to M1 splice and the recognition of the $\mu_{s}$ poly $(\mathrm{A})$ cleavage site. They argued that deletion of intron sequence, by reducing the distance between the splice donor and acceptor, might improve the efficiency of splicing. This conclusion is in contrast to our suggestion that the control may involve poly(A) site competition. At the present time there is no clear evidence to allow a discrimination between these two possible mechanisms, although we would point out that there is no evidence for an effect of intron size on splicing efficiency. Also, we do find that when the two poly $(\mathrm{A})$ sites are separate, and thus $\mu_{\mathrm{m}}$ splicing cannot compete against $\mu_{\mathrm{s}}$ poly $(\mathrm{A})$ site formation, the production of $\mu_{\mathrm{m}}$ RNA greatly exceeds that of $\mu_{s}$ (Fig. 2). The simplest interpretation is that the $\mu_{\mathrm{m}}$ poly $(\mathrm{A})$ site is stronger than the $\mu_{\mathrm{s}}$ and this, combined with their relative position within the transcription unit, is responsible for the near-equal expression in a mature B cell.

The mechanism for transcription termination in this locus, and in particular the regulated termination, remains obscure as it does for the other examples of polymerase II termination. However, an analysis of the effect of the intron deletions on termination does provide some insight into the process. First, the degree of relief of termination was gradual and was a function of the size of the deletion. This observation could be reconciled in at least two ways. There could be multiple termination signals, the removal of a single one of which does not eliminate termination. However, their effect must be additive since termination was gradually reduced as the deletions increased. We favor an alternative explanation. The deletions may not have removed a termination signal but rather just a spacer sequence between the signal and the site of termination. For instance, if a sequence element directed termination at a distance roughly $1 \mathrm{~kb}$ downstream, irrespective of the sequence at that position, then deletion of 500 nucleotides between the signal and the termination site would still result in termination $1 \mathrm{~kb}$ downstream of the signal, but now at a sequence 500 nucleotides further downstream than the original site. Thus, sequences not normally transcribed would now be transcribed as a result of the deletion; in this case, the $\mu_{m}$ poly(A) site. What might this signal be? A likely candidate is the poly(A) site, in this example the $\mu_{s}$ poly(A) site. Evidence sup-

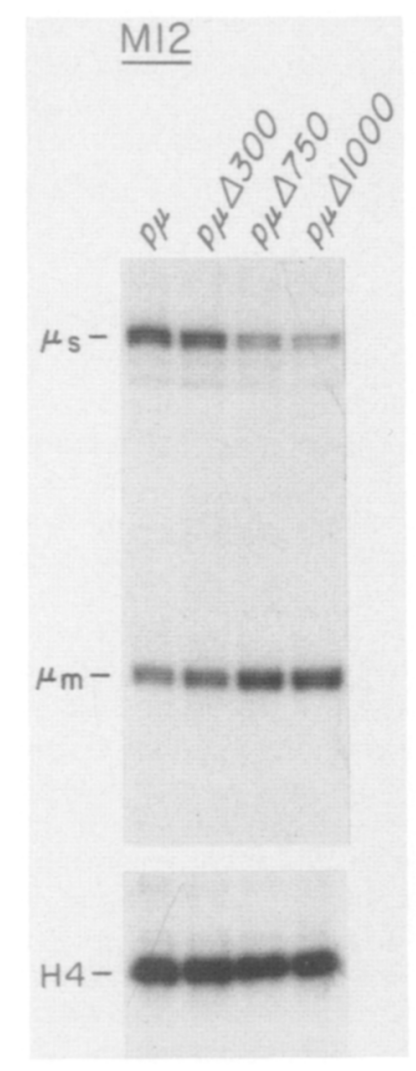

Figure 7. Expression of the $\mathrm{p} \mu$ intron deletion mutants in $\mathrm{M} 12$ cell transfections. S1 mapping of RNAs produced in M12 cells transfected with the intron deletions. RNAs were assayed as described in Fig. 4. 
porting this comes from analyses of both the $\beta$-globin transcription unit (Falck-Pederson et al. 1985) and the $\alpha$-globin transcription unit (Whitelaw and Proudfoot 1986) where it was clear that termination depended on a functional poly(A) site. This interpretation is also consistent with the expression of plasmids in which the $\mu_{\mathrm{s}}$ poly(A) site has been deleted. Both our experiment with the $\mathrm{p} \mu_{\mathrm{m}}$ plasmid (Fig. 2) and the similar experiment of Danner and Leder (1985) indicated that there is efficient production of $\mu_{\mathrm{m}}$ RNA in plasmacytomas when the $\mu_{\mathrm{s}}$ poly $(\mathrm{A})$ site is deleted.

Although there is evidence for transcription termination from measurements of the $\mu$ locus in plasmacytomas and hybridomas (Kelley and Perry 1986), a similar study of the $\delta$ locus indicated that termination did not play a role in the switch from membrane to secreted RNA expression (Milcarek and Hall 1985). Firm conclusions concerning the $\delta$ locus may be premature since only one plasmacytoma was scored and the assays have not been done in the absence of any potential background transcription. However, it is also possible that the control of $\mu_{\mathrm{m}}$ expression by transcription termination is due to the unique arrangement of the $\mu-\delta$ locus. The $\mu$ and $\delta$ loci are transcriptionally linked and the cessation of $\delta$ RNA production during B-cell maturation is the result of transcription termination prior to the $\delta$ exons (Yuan and Tucker 1984; Mather et al. 1984). Possibly this unique transcription unit complexity dictates a control of termination not found for the other heavychain loci.

\section{Control of the $\mu$ transcription unit during B-cell development}

From all of the data presented here, we propose the following as a likely scenario for the events that dictate expression of the $\mu$ transcription unit. In the B cell that is expressing roughly equal amounts of secreted and membrane-bound $\mu$ chains, transcription proceeds unabated through $\mu_{m}$, generally terminating just upstream of the $\delta$ exons, although some transcripts clearly proceed through the $\delta$ exons (Mather et al. 1984; Yuan and Tucker 1984). The ratio of $\mu_{s}$ to $\mu_{m}$ RNA production is dictated by the relative strengths of the poly(A) sites and the fact that the $\mu_{\mathrm{m}}$ is situated considerably downstream of the $\mu_{\mathrm{s}}$ site. In a pre-B cell where the level of $\mu_{\mathrm{m}}$ is considerably greater than $\mu_{s}$ we would predict that there is a very low amount of a poly(A) site factor such that the inefficient $\mu_{s}$ poly(A) site is rarely used. When the mature $B$ cell encounters antigen and differentiates into a plasma cell, we suggest that two events take place. First, there is a further increase in a poly(A) site factor (beyond that which has occurred in the change from a pre-B cell to mature $B$ cell) to ensure even greater use of the $\mu_{s}$ poly(A) site. And, to eliminate any competition by the $\mu_{\mathrm{m}}$ site and thus further increase the use of the $\mu_{\mathrm{s}}$ site, transcription terminates prior to the $\mu_{\mathrm{m}}$ poly(A) site, thus eliminating it from the primary transcript. Interestingly, it is possible to reconcile these two phenomena as a single event if indeed termination is triggered by the use of the poly(A) site as suggested above.
That is, as the $\mu_{\mathrm{s}}$ poly(A) site is used with greater frequency due to an increased level of factor, termination ensues. As termination decreases the synthesis of the $\mu_{m}$ poly(A) site, there is less competition with the $\mu_{s}$ and thus greater use of the $\mu_{\mathrm{s}}$ poly $(\mathrm{A})$ site and therefore more termination. Such a mechanism could clearly drive the expression to exclusive production of $\mu_{\mathrm{s}}$.

Finally, it is also known that in addition to the selective use of the $\mu_{s}$ poly $(\mathrm{A})$ site in plasma cells, there is a large increase in $\mu$ mRNA when $B$ cells mature to plasma cells without a commensurate increase in transcription (Yuan and Tucker 1984; Kelley and Perry 1986; Gerster et al. 1986). We have not observed large increases in total $\mu$ mRNA in the transfected M12 and J558L cells, a result consistent with previous observations (Grosschedl and Baltimore 1985). As suggested by these authors, the most likely explanation is the nature of the assay, a transient transfection with a replicating plasmid. If the large increase in $\mu$ RNA normally seen when lymphocytes differentiate is due to increased RNA stability, then a short-term assay might not allow sufficient time for the effect to be established. This interpretation is further supported by our observation that stably transfected $\mathrm{J} 558 \mathrm{~L}$ cells produce at least 10 -fold more $\mu$ RNA than stable M12 transfectants (J. Guise et al., in prep.). Thus, it is quite possible that three separate aspects of mRNA biogenesis contribute to the final $\mu_{\mathrm{s}}$ RNA-dominant phenotype of the plasma cell: changing concentration of a poly(A) site factor, transcription termination to eliminate use of the $\mu_{\mathrm{m}}$ poly(A) site, and increased stability of the $\mu$ RNA.

\section{Materials and methods}

\section{Cell culture and transfections}

The J558L cell line was grown in DME supplemented with $10 \%$ fetal calf serum. The M12 cell line was grown in RPMI containing $10 \%$ fetal calf serum. Transfections were performed as described by Grosschedl and Baltimore (1985). The cells were harvested after $40 \mathrm{hr}$ and total RNA was isolated and purified as described by Chirgwin et al. (1979).

\section{Construction of plasmids}

The DNA construct referred to in this paper as $p \mu$ is the $\mathrm{p} \mu \Delta 3$ plasmid described by Grosschedl and Baltimore (1985). To construct the $\mu_{\mathrm{s}}$ plasmid, the $1.8 \mathrm{-kb} E c o \mathrm{RV}-X$ hol fragment was deleted. To construct the $\mu_{\mathrm{m}}$ plasmid, the $1.2-\mathrm{kb} B c I I-E c o R V$ fragment was deleted. To construct the $p \mu_{\mathrm{m} / \mathrm{s}}$ plasmid, the 1.4$\mathrm{kb} B c$ II fragment containing the $\mu_{\mathrm{s}}$ poly(A) site was inserted into the XhoI site of the $\mathrm{p} \mu_{\mathrm{m}}$ plasmid. The intron deletions were created by Bal3l digestion starting at the EcoRV site. The extent of the deletions was determined by restriction enzyme mapping.

\section{S1 nuclease assays}

Approximately $10-30 \mu \mathrm{g}$ of total RNA was hybridized with ${ }^{32} \mathrm{P}$-end-labeled probes. The hybridization temperature was $46^{\circ} \mathrm{C}$ for the $\mu$-specific probes and $50^{\circ} \mathrm{C}$ for the $\mathrm{H} 4$-specific probe. The hybrids were digested with 50 units of $\mathrm{S} 1$ nuclease (PL Biochemicals) at $37^{\circ} \mathrm{C}$ for $1 \mathrm{hr}$. The protected DNA fragments were analyzed by electrophoresis in $8 \%$ acrylamide-urea gels. 


\section{Transcription analysis in isolated nuclei}

For each transcription rate measurement, $2-4 \times 10^{8}$ cells were transfected and harvested $40 \mathrm{hr}$ later. The procedures for isolation of nuclei, in vitro incubation, and isolation and hybridization of labeled nuclear RNA have been described previously (Weber et al. 1977; Hofer and Darnell 1981). For each assay, approximately $2 \times 10^{8}$ nuclei were incubated with $500 \mu \mathrm{Ci}$ of [32 P]UTP for $15 \mathrm{~min}$ at $30^{\circ} \mathrm{C}$. Nuclear RNA was isolated by hot phenol extraction and before hybridization was partially broken by incubation in $0.2 \mathrm{~N} \mathrm{NaOH}$ for $15 \mathrm{~min}$ on ice. Nitrocellulose filters bearing the various M13 single-stranded (ss) DNA probes were prepared as described by Kafatos et al. (1979). The M13 probes used were: probe $a$ derives from a cDNA spanning part of the $\mathrm{C} \mu 2$ exon (from a PvuII site), the $\mathrm{C} \mu 3$ exon, and part of the $\mathrm{C} \mu 4$ exon (to the PstI site) and has a total length of 761 nucleotides; probe $b$ is a 610-nucleotide PstI-HindIII fragment containing the $\mu_{\mathrm{s}}$ poly(A) site; probe $c$ is a 916-nucleotide KpnI-HincII fragment; probe $d$ is a 200 -nucleotide Rsal fragment; probe $e$ is a 400 -nucleotide SphI-Xhol fragment; probe $P y$ is a 1400 -nucleotide $X h o I-E c o R I$ fragment of polyomavirus DNA. All probes were cloned into the polylinker of M13 mpl8 and M13 mp19.

\section{Acknowledgments}

We thank Dr. Rudolph Grosschedl for the gift of the p $\mu$ plasmid as well as for valuable advice. We also thank Caroline Glover and Chhaya Das for technical assistance. G.G. was supported by fellowships from EMBO and the Swiss National Science Foundation. M.M. is an MSTP fellow. The work was supported by National Institutes of Health grants AI 18016 and GM 31689 to P.T. and GM 35894 to J.N.

\section{References}

Alt, F.W., A.L.M. Bothwell, M. Knapp, E. Siden, E. Mater, M. Koshland, and D. Baltimore. 1980. Synthesis of secreted and membrane-bound immunoglobulin mu heavy chains is directed by mRNAs that differ at their $3^{\prime}$ ends. Cell 20: 293 302.

Alt, F.W., N. Rosenberg, V. Enea, E. Siden, and D. Baltimore. 1982. Multiple immunoglobulin heavy chain gene transcripts in Abelson murine leukemia virus transformed lymphoid cell lines. Mol. Cell. Biol. 2: 386-400.

Birnstiel, M.L., M. Busslinger, and K. Strub. 1985. Transcription termination and $3^{\prime}$-processing: The end is in site. Cell 41: 349-359.

Blattner, F.R. and P.W. Tucker. 1984. The molecular biology of immunoglobulin D. Nature 307: 417-422.

Chirgwin, T.M., A.E. Przybyla, R.J. MacDonald, and W.J. Rutter. 1979. Isolation of biologically active ribonucleic acid from sources enriched in ribonuclease. Biochemistry 18: $5294-5299$.

Danner, D. and P. Leder. 1985. Role of an RNA cleavage/poly|A) addition site in the production of membrane-bound and secreted IgM mRNAs. Proc. Natl. Acad. Sci. 82: 8658-8662.

Early, P., J. Rogers, M. Davis, K. Calame, M. Bond, R. Wall, and L. Hood. 1979. Two mRNAs can be produced from a single immunoglobulin $\mu$ gene by alternative RNA processing pathways. Cell 20: 313-319.

Falck-Pedersen, E., J. Logan, T. Shenk, and J.E. Darnell, Jr. 1985. Transcription termination within the E1A gene of adenovirus induced by insertion of the mouse $\beta$-major globin terminator element. Cell 40: 897-905.

Gerster, T., D. Picard, and W. Schaffner. 1986. During B-cell differentiation enhancer activity and transcription rate of immunoglobulin heavy chain genes are high before mRNA accumulation. Cell 45: 45-52.

Grosschedl, R. and D. Baltimore. 1985. Cell-type specificity of immunoglobulin gene expression is regulated by at least three DNA sequence elements. Cell 41: 885-897.

Hofer, E. and J.E. Darnell, Jr. 1981. The primary transcription unit of the mouse $\beta$-major globin gene. Cell 23: 585-593.

Kafatos, F.C.C., W. Jones, and A. Efstradiadis. 1979. Determination of nucleic acid sequence homologies and relative concentrations by dot hybridization procedure. Nucleic Acids Res. 7: 1541-1551.

Kelley, D.E. and R.P. Perry. 1986. Transcriptional and posttranscriptional control of immunoglobulin mRNA production during B lymphocyte development. Nucleic Acids Res. 14: $5431-5447$.

Laskov, R., J.K. Kim, V.L. Woods, P.E. McKeever, and R. Asofsky. 1981. Membrane immunoglobulins of spontaneous B-lymphomas of aged BALB/c mice. Eur. I. Immunol. 11: $462-468$.

Lennon, G.G. and R.P. Perry. 1985. $C_{\mu}$-containing transcripts initiate heterogeneously within the IgH enhancer region and contain a novel $5^{\prime}$-nontranslatable exon. Nature 318: 475478.

Mather, E.L., K.J. Nelson, J. Haimovich, and R.P. Perry. 1984. Mode of regulation of immunoglobulin mu and delta chain expression varies during B lymphocyte maturation. Cell 36: $329-338$.

Milcarek, C. and B. Hall. 1985. Cell-specific expression of secreted versus membrane forms of immunoglobulin gamma 2b mRNA involves selective use of alternate polyadenylation sites. Mol. Cell. Biol. 5: 2514-2520.

Nelson, K.J., J. Haimovich, and R.P. Perry. 1983. Characterization of productive and sterile transcripts from the immunoglobulin heavy-chain locus: Processing of $\mu_{\mathrm{m}}$ and $\mu_{\mathrm{s}}$ mRNA. Mol. Cell. Biol. 3: 1317-1332.

Nevins, J.R. 1979. Processing of late adenovirus nuclear RNA to mRNA: Kinetics of formation of specific intermediates and demonstration that all events are nuclear. $J$. Mol. Biol. 130: 493-506.

1983. The pathway of eukaryotic mRNA formation. Annu. Rev. Biochem. 52: 441-466.

Nevins, J.R. and J.E. Darnell. 1978. Steps in the processing of Ad-2 mRNA: Poly $(A)^{+}$nuclear sequences are conserved and poly(A) addition precedes splicing. Cell 15: 1477-1493.

Nevins, J.R. and M.C. Wilson. 1981. Regulation of adenovinus-2 gene expression at the level of transcriptional termination and RNA processing. Nature 290: 113-118.

Oi, V.T., S.L. Morrison, L.A. Herzenberg, and P. Berg. 1983. Immunoglobulin gene expression in transformed lymphoid cells. Proc. Natl. Acad. Sci. 80: 825-829.

Padgett, R.A., P.J. Grabowski, M.M. Konarska, S. Seiler, and P.A. Sharp. 1986. Splicing of messenger RNA precursors. Annu. Rev. Biochem. 55: 1119-1150.

Perry, R.P. and D.E. Kelley. 1979. Immunoglobulin messenger RNAs in murine cell lines that have characteristics of immature B lymphocytes. Cell 18: 1333-1339.

Peterson, M.L. and R.P. Perry. 1986. Regulated production of $\mu_{m}$ and $\mu_{s}$ mRNA requires linkage of the poly(A) addition sites and is dependent on the length of the $\mu_{s}-\mu_{m}$ intron. Proc. Natl. Acad. Sci. 83: 8883-8887.

Rogers, J., P. Early, C. Carter, K. Calame, M. Bond, L. Hood, and R. Wall. 1980. Two mRNAs with different $3^{\prime}$ ends encode membrane-bound and secreted forms of immunoglobulin $\mu$ chain. Cell 20: 303-312.

Ruether, J.E., A. Maderious, D. Lavery, J. Logan, S.M. Fu, and S. 
Chen-Kiang. 1986. Cell-type-specific synthesis of murine immunoglobulin $\mu$ RNA from an adenovirus vector. Mol. Cell. Biol. 6: 123-133.

Weber, J., W. Jelinek, and J.E. Darnell. 1977. The definition of a large viral transcription unit late in Ad2 infection of HeLa cells: Mapping of nascent RNA isolated nuclei. Cell 10: 611-616.

Whitelaw, E. and N. Proudfoot. 1986. $\alpha$-Thalassaemia caused by a poly(A) site mutation reveals that transcriptional termination is linked to $3^{\prime}$ end processing in the human $\alpha 2$ globin gene. EMBO J. 5: 2915-2922.

Yuan, D. and P.W. Tucker. 1984. Transcriptional regulation of the $\mu-\delta$ heavy chain locus in normal murine B lymphocytes. I. Exp. Med. 160: 564-583. 


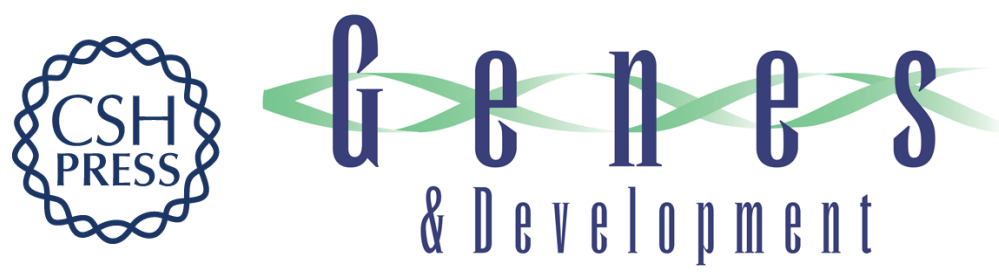

\section{Relative position and strengths of poly(A) sites as well as transcription termination are critical to membrane versus secreted mu-chain expression during B-cell development.}

G Galli, J W Guise, M A McDevitt, et al.

Genes Dev. 1987, 1:

Access the most recent version at doi:10.1101/gad.1.5.471

References This article cites 31 articles, 8 of which can be accessed free at: http://genesdev.cshlp.org/content/1/5/471.full.html\#ref-list-1

License

Email Alerting

Receive free email alerts when new articles cite this article - sign up in the box at Service the top right corner of the article or click here.

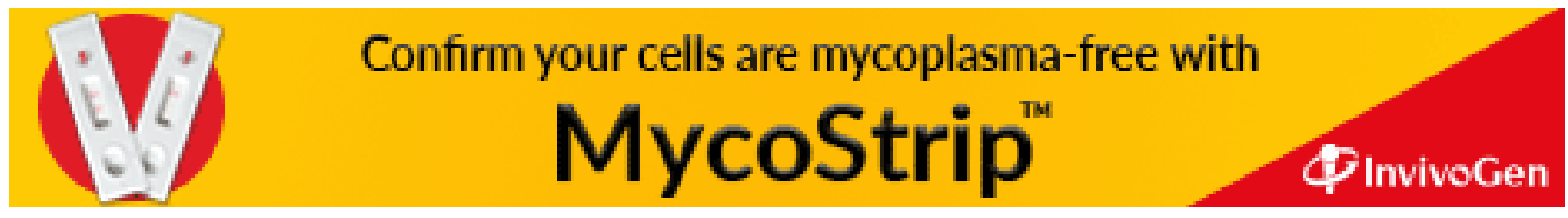

